\title{
Life Cycle - A New Revolution
}

\section{Richard Chuang}

Editor's note: This article is adapted from a lecture by Richard Chuang, a two Motion Picture Academy Technical Awards for his pioneering work in digital animation and visual effects, during July 2016 first-annual Future of Health: Telemedicine and Al summit in Ho Chi Minh City, Vietnam.

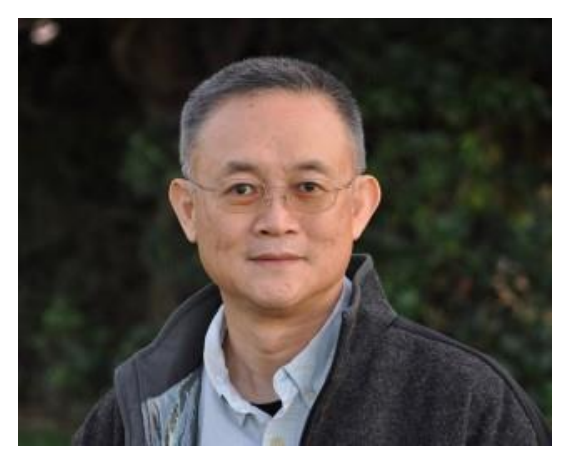

Change is in the air. The recent advances in deep learning (software that attempts to mimic the activity in layers of neurons in the neocortex) and visual computing with VR/AR (augmented reality/virtual reality) are redefining the tools and speed of innovation in the medical field.

Throughout history, industries have evolved in cycles that go from inception through rapid growth to maturity. Each cycle generated disruptive changes in society. While the earlier revolutions spanned multiple generations, more recent revolution cycles are increasingly compressed, leaving less time for society to adapt and integrate each advancement (Table 1).

Table 1. Recent revolutionary changes and the changes they cause

Duration

1760-1820
Revolution

First Industrial Revolution
Outcome

Mass production 

1870-1914
Technology Revolution
Communication,
Transportation
1950-current
Digital Revolution
Information,
Computation
2012-???
Al Revolution
Deep Learning

Al: artificial intelligence

\section{Computers Were Just Too Slow!}

It has been 37 years since I dropped out of graduate school for biomedical engineering, because computers were just too slow! Back in 1980, a small group of us started a company, Pacific Data Images (PDI), and formed a new industry using computers to generate graphics for art and entertainment.

We built the industry from inception to maturity in just 35 years. Within one generation, the industry went through the whole revolution cycle. We were one of the first to be able to see a new industry evolve in such a short time span. (Figure 2)

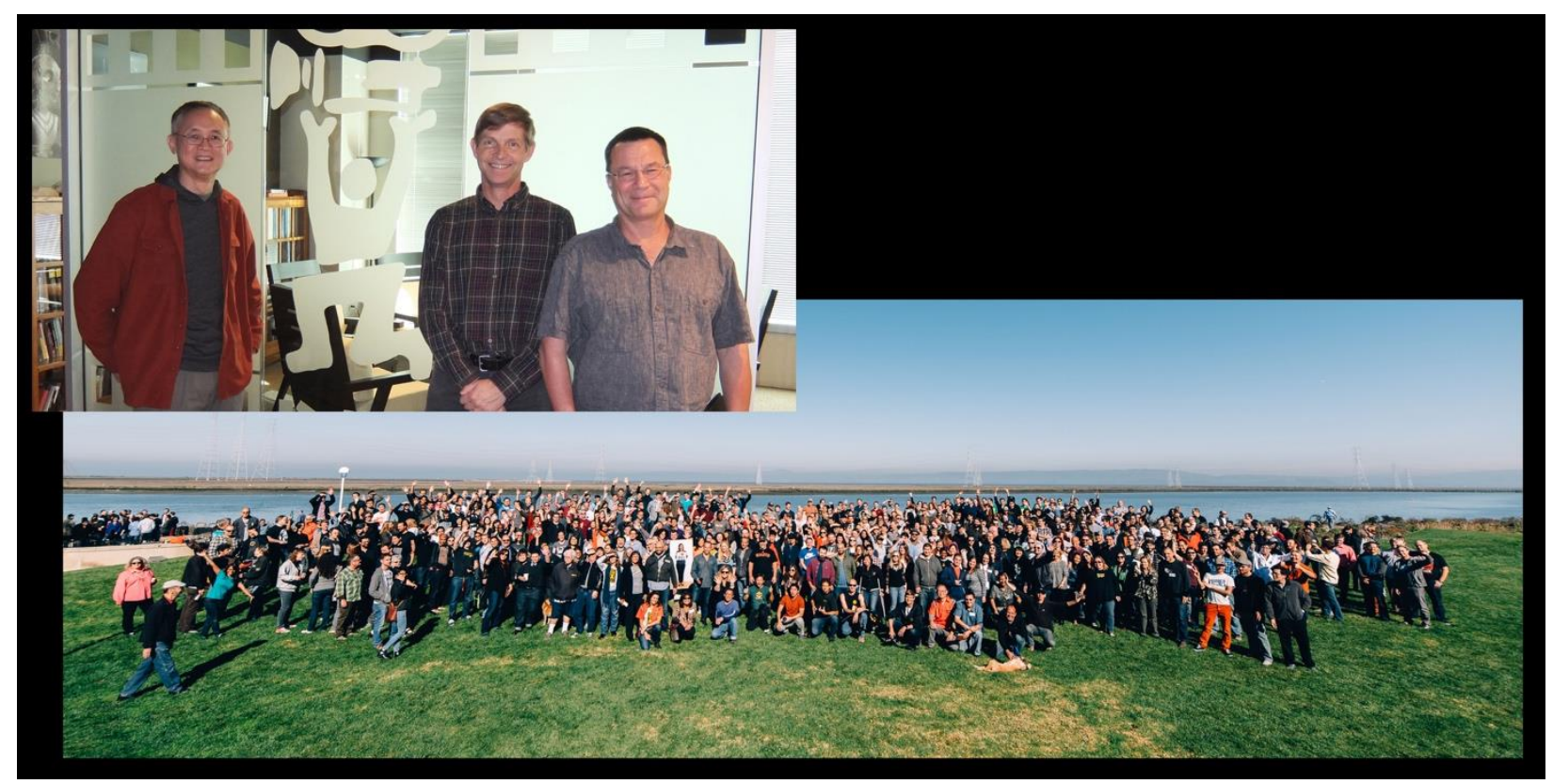

Figure 2. PDI growth in personnel from 1980 to 2015. Upper left shows PDI founders: Richard Chuang, Carl Rosendahl and Glenn Entis 
The challenge to stay competitive in such a quickly evolving technology-based industry taught us many invaluable lessons about staying innovative and keeping up with change. But compared to our seemingly short life cycle in computer graphics, the current revolution initiated with the recent advancement in deep learning appears to be moving at an even quicker pace.

\section{A New Horizon in Machine Intelligence}

Artificial Intelligence $(\mathrm{Al})$ is a term that has encompassed many technologies over the years. Only in recent years have deep learning and computing power opened a new horizon in machine intelligence. We have finally reached an age where machine learning can be practical as a tool and a solution for everyday problems.

While we were in awe at the advances in Google's AlphaGo (a computer program developed by Google DeepMind in London to play the board game Go) and IBM's Watson (a computer system capable of answering questions posed in natural language), the advancement in deep learning is quickly encroaching into many aspects of our daily lives.

From the perspective of many researchers, obstacles such as spoken language and visual recognition are now solved. Deep learning is becoming the go-to solution for many of our daily challenges like office work in the finance and legal arena. You might be already dealing with digital assistants without the awareness of their presence.

In the field of medicine, machine learning will quickly extend beyond serving as an intelligent assistant and become a vital tool for medical professionals. Watson is just the beginning. Intelligent-connected devices in the world of Internet-of-Things (IoT) will improve the life and care of individuals with a personal touch. ${ }^{1}$ Advances in visual communication in the field of VR/AR will connect and enhance communication in telemedicine and between people and machines. Visual computing assisted by deep 
learning will recognize and deliver vital medical information to both the doctors and patients. ?

\section{The Challenge Ahead}

This revolution will move faster than anything seen before. We need to be much more prepared to ride this wave and have intelligent conversations dealing with the consequences and implications of the rapid progress in how we work and solve problems. This is a life cycle we cannot just sit back and watch because much of what we will do and learn will change.

Richard Chuang has won two Motion Picture Academy Technical Awards for his pioneering work in digital animation and visual effects. He is also one of the original founders of PDI/Dreamworks, an Emmy graphics design winner, and the visual effects supervisor for 16 live action films.

Tags: Al revolution, AlphaGo, artificial intelligence, augmented reality, deep learning, DeepMind, digital assistants, digital revolution, Emmy graphics design winner, Future of Health: Telemedicine and AI Symposium, Ho Chi Minh City, intelligent-connected devices, Internet-of-Things, loT, life cycle, PDI/Dreamworks, Richard Chuang, Telehealth, telemedicine, virtual reality, VR/AR, Watson, what is telemedicine and how does it work

References

1. Burrus D. The Internet of Things is far bigger than anyone realizes. Wired. 2016. URL: http://www.wired.com/insights/2014/11/the-internet-of-things-bigger/. Accessed 8/22/16.

2. Cashin-Garbutt A. How can deep learning impact healthcare? News Medical. 2016. URL: http://www.news-medical.net/news/20160408/How-can-deeplearning-impact-healthcare.aspx. Accessed 8/22/16. 